Article

\title{
The Need for New Product Development Capabilities from Digitalization, Sustainability, and Servitization Trends
}

\author{
Sophie I. Hallstedt ${ }^{1, *(\mathbb{D},}$, Ola Isaksson ${ }^{2}$ (i) and Anna Öhrwall Rönnbäck ${ }^{3}$ (]) \\ 1 Department of Strategic Sustainable Development, School of Engineering, Blekinge Institute of Technology, \\ SE-37179 Karlskrona, Sweden \\ 2 The Division of Product Development, Department of Industrial and Materials Science, \\ Chalmers University of Technology, SE-41296 Gothenburg, Sweden; ola.isaksson@chalmers.se \\ 3 The Division of Humans and Technology, Department of Business Administration, \\ Technology and Social Sciences, Luleå University of Technology, SE-97187 Luleå, Sweden; \\ anna.ohrwall.ronnback@ltu.se \\ * Correspondence: Sophie.Hallstedt@bth.se
}

Received: 1 November 2020; Accepted: 3 December 2020; Published: 7 December 2020

\begin{abstract}
Apparent from the latest pandemic, the dynamics and rate of change in society accelerate on a global scale. Ongoing mega-trends in society, such as digitalization, sustainability, and servitization, fundamentally changes the conditions for manufacturers when developing and providing new products. This study clarifies the combined impact and consequences on product development capabilities in manufacturing firms of the three mega-trends: (i) digitalization, (ii) sustainability, and (iii) servitization. The research is based on a pre-study, complemented with a semi-structured interview study at small, medium-sized, and large Swedish-based manufacturing companies, and a systematic literature review. The research makes evident that the main challenge is to empower engineers and development teams to model, present, evaluate, and develop expected and smart digitalized solutions in a time-limited environment and prioritize the most resource efficient and sustainable solution. Therefore, four complementary support resources are suggested: (i) a knowledge management platform, (ii) a data management platform, (iii) a set of criteria and metrics measuring progression, and (iv) support methods and tools to define, model, and evaluate solutions. When integrated into a digital platform, developers can simultaneously access and process the necessary information needed for sustainable, digitalized, and servitized solutions.
\end{abstract}

Keywords: digitalization; sustainability; servitization; trends; sustainable product development; product-service systems; manufacturing companies; design capabilities

\section{Introduction}

The next generation products will need to be designed to meet market and societal needs while utilizing technology advancements and careful use of resources. The results will be products and human-made systems that play an increasingly interwoven role in our society [1,2]. Consequently, the manufacturers will need to understand well the dominant trends that currently change our society. We live in a society that undergoes a sustainable transition, and a digital transition, where value is determined by what services are provided. These societal transitions have a profound impact not only on our daily life, but also on companies' methods and processes used to develop products and systems. Evident from the ongoing pandemic is that the rate of change in society is also dramatically increasing [3]. Development processes, methods, tools, competences, and ways of organizing development work need to evolve rapidly. The competitiveness of manufacturers lies 
within their ability to adapt and develop efficient and effective practices to develop the needed solutions in future [4]. Many manufacturing companies use methods and processes that have been developed to handle predominately single domain engineering problems, such as mechanical, electrical, or software problems. Artifacts produced are increasingly multi-technological, embedding service offerings. Such business models rely on the artifact's behavior; the driving forces in society call for sustainable and life-cycle integration, and there are questions for how to best develop and manage such integrated solutions. Today, digitalization radically brings software into products, and services constitute an increasingly large share of revenue for many manufacturers; Rolls Royce, for example, reported 52 percent of revenue from services in their annual report from 2017 [5]. What can we learn from some different types of manufacturing companies today on how to act in a world moving fast into a transitional global change? The purpose of this study is to clarify the combined impact and consequences on product development capabilities in manufacturing firms of the three mega-trends: (i) digitalization, (ii) sustainability, and (iii) servitization, and build further on a pre-study conducted by the authors and presented in Nord Design 2018 [6]. In this study, an in-depth investigation is conducted to find the possibilities and challenges that companies perceive today with respect to meeting the three mega-trends: digitalization, sustainability, and servitization, and, more specifically, how these trends collectively impact the design and development capabilities in product development companies. Capabilities are here defined according to [7] (p. 38) as "complex bundles of skills and accumulated knowledge, exercised through organizational processes that enable firms to coordinate activities and make use of their assets." The particular focus is to answer the research questions: What are the main findings and proposals in previous research in the combined field of the three product development capabilities of: (i) Digitalization, (ii) Sustainable Product Development (SPD), and (iii) Product-Service Systems (PSS), related to manufacturing companies? How do manufacturing industry representatives perceive the potential of combining these areas for innovation?

\section{Background}

Numerous studies exist that analyze each of these mega-trends individually, e.g., [8-11] and their impact on society and industry. Less clear is their impact on design and product development, and in what way design and development capabilities are affected. Design and development in the early stages in the product innovation process [12] are good examples of "integrative" business processes that later can be produced and offered. Product development, following, e.g., [13], covers the series of activities starting with the identification of market needs and the delivery of product definitions for manufacturing and sales. The three trends have in common their broad and overarching impact on the development of society, as well as a detailed impact on companies' business models and solutions to meet the needs in society. As the variables of such solutions are likely to influence the artefact, also likely to be affected are the life-cycle dimensions, product-service system interactions, value constellations [14], and the established design capabilities. De Neufville and Scholtes [15] argued, therefore, that development capabilities need to better predict and manage uncertainties induced by the evolving society and to ensure that design approaches are more adaptable and flexible. Subrahmanian et al. [2] conclude that the theoretical basis in engineering design need to better include the societal and contextual factors.

The paper is organized as follows: in the remainder of the background, the three product development capabilities that address the three mega-trends are described, i.e., digitalization, SPD, and PSS. A method description follows in Section 3, and Section 4 presents a summary of the literature review, regarding the combined subjects of digitalization, sustainability, and servitization related to manufacturing companies. In Section 5, results from eight case companies are discussed regarding their perceived potentials in industry to combine these three areas to develop innovative and valuable solutions. Section 5 also looks into how the manufacturing industry's capabilities for product development are affected by these three trends in society. Finally, the paper discusses and 
concludes, in Sections 6 and 7, some main findings and learnings from manufacturing companies on how to act in a world moving fast in a transitional change.

\subsection{Product Development in Industry 4.0-Digitalization}

The digital economy is central to development and growth in Europe, as outlined by the European president-elect Juncker in 2014 [16]. In the 2017 version of the scoreboard [17] monitoring the progress of digital transformation in Europe, it was stated that $75 \%$ of respondents from Automotive, Mechanical, and Healthcare and Pharmaceutical industries regarded digital technologies as an opportunity, and $44 \%$ of the companies investing in digital technologies had generated a positive outcome. Still, only $47 \%$ considered that they had the necessary skills over the last three years to adopt new technologies. It seems evident that the digital transformation has a broad impact on society in general and is a fundament for what is often called the fourth industrial revolution.

Digitalization is the term commonly used to denote the use of digital data, and for product development we here refer to the use of digitized information to support and enable product development. In this way, the product development is a part of the concept of Industry 4.0 [18]. Practical examples include the use of digital guidelines, capturing and using data generated in all phases of the life-cycle for the purpose of product development, as well as digital capabilities to manage and process the increasing amount of data generated.

One characteristic of digitalization is the explosion of the amount of data being generated in all phases of the life-cycle. Engineers in product development have the ability to benefit from the vast amount of information measured in both production processes and when products are in use using so-called "digital twins" [19]. Less evident is how companies benefit from the data being generated within design iterations. Theoretically, and practically, data can be communicated nearly instantly independent of geographical location. How to benefit from these data in design situations is less clear and require new practices and new ways of working. The experience, trust, and set of digital design practices have matured over decades within separate disciplines. A question is to what extent this is helpful, or a hindrance, to utilizing a multidisciplinary, integrated, and global data availability context. Hence, it is important to understand the needs and opportunities that industry faces and how these are tackled in practice.

\subsection{Sustainable Product Development}

Sustainable development is widely addressed in society, where, e.g., the UN2030 sustainable development goals [20] are being implemented into regional and national agendas and regulations and in this way impacting the direction of development also for manufacturing industries. Also, the market reality reveals clearly a shift in trust for the carbon economy, and the availability of natural resources impacts directly market prices of minerals. The linear resource society is not seen as a viable solution, which is why the interest in circular economy solutions is booming [21,22]. Many product development companies face tougher regulations and increased life-cycle responsibilities, and the electrification of powerplants is already underway. To steer into a more sustainable development path not only requires small changes in line with tougher legislation but also radical improvements and innovations. Sustainability-driven innovations are profitable [9] and empirical studies indicate a positive effect of sustainable product innovation on overall company performance [23,24]. A way for manufacturing and product development companies to respond to the sustainability trend is to apply the Sustainable Product Development (SPD). This means that a strategic sustainability perspective is integrated and implemented into the early phases of the product innovation process, including life-cycle thinking [25]. Working strategically with corporate sustainable development means that efforts are guided by a unifying vision of what sustainability means for the company. At the same time, it is crucial that a complete socio-ecological sustainability perspective is applied, rather than focusing only on a few sustainability aspects, which leads to a risk of sub-optimization and negative long-term sustainability consequences [26]. To explain sustainability, a principled definition of sustainability that describes 
the boundary conditions within which a sustainable society has to operate is therefore used here. These principles can also be regarded as the root causes of unsustainability for the ecological and social systems. The current phrasing of the sustainability principles is as follows [27] (p. 23): "In a sustainable society, nature is not subject to systematically increasing ...

1. ... concentrations of substances extracted from the Earth's crust.

2. ... concentrations of substances produced by society.

3. ... degradation by physical means.

and people are not subject to structural obstacles to ...

4. ... health.

5. $\quad \ldots$ influence.

6. $\quad \ldots$ competence.

7. ... impartiality.

8. ... meaning-making."

These sustainability principles clarify what is required for sustaining the social and ecological systems so that their potential to support the fulfilment of human needs are not systematically degraded. No economical sustainability principles are defined. Instead, the economy should be seen as a mean for companies to make tactical decisions and necessary investments to deliver more sustainable solutions. Economical aspects, e.g., innovation and technology, collaboration, knowledge management, processes, purchase, and sustainability reporting [28], can, however, be used to guide business success of an organization in a transitional change towards a more sustainable society.

Businesses clearly express a need to be able to increase their abilities to work with sustainability [29], and the main company driving forces for investing in building capabilities for sustainable product development and innovation are increased competitiveness, legal requirements, brand and reputation, and employee motivation [30,31]. The problem today is that few companies have succeeded in integrating and implementing sustainability, especially at the more operational level as it is not concretized and integrated with other technical parameters [32]. Today there are several examples of more sustainable solutions from manufacturing companies, such as a reduced need for lubricating oils in the usage phase, improved hydraulics that optimizes and makes the machines more energy efficient, lower weight, which reduces the material usage and makes the machines more energy efficient in the usage phase, and a longer service life that also is a more material- and energy-efficient solution. In total, these are typical examples of solutions that can give a better sustainability profile of a product. However, many of these solutions are more of a coincidence than a conscious and systematic approach of sustainable product development. Previous studies have shown that there is a potential to adopt a more systematic approach for sustainable product development $[25,33,34]$.

\subsection{Product-Service Systems}

Product-Service Systems (PSS) is commonly used to give manufacturers a framework to articulate business offers in the servitization economy [11]. It can be considered to be a solution or a strategy where value is provided by combining the artefact, its services and enabling infrastructure, often delivered at an already installed resource base [35]. In general, PSS solutions can form a platform to maximize the value of products and materials, and thereby also create circular economy strategies [36,37]. The portion of service sales for manufacturing industries is increasing, e.g., [38], and is clearly connected to innovation. It is also reported that the revenue from services versus product sales is increasing [39].

The PSS demands call for organizational transformations and manufacturers therefore need to develop new competencies and capabilities to become providers of integrated solutions $[40,41]$. The development of PSS is challenged by the different characteristics of its constituting parts, i.e., mainly the tangible product and the intangible service components. Generally, a PSS offering integrates the 
business model as a part of the solution, which means that the design and development of both tangible products and services are strongly linked to how the manufacturer chose to provide the PSS. One key factor is to understand and design the PSS, taking into account who has the responsibility for, e.g., availability and the upgrade of the solution. Service innovation follows a different logic than product innovation [42], and manufacturers need to find ways to combine product and service innovation effectively.

\section{Research Methods}

This study builds on a pre-study conducted by the authors and presented in Nord Design 2018 [6]. In this study, an in-depth investigation is conducted and consists out of two main parts: (i) a theoretical part that includes a structural review [43] of current literature; and (ii) an empirical part, including a descriptive multiple case study of eight companies.

\subsection{Systematic Literature Review}

A structural literature review was conducted with the purpose to synthesize and gain new perspectives of the combined subjects of digitalization, sustainability, and servitization, related to manufacturing companies, with the specific research question: What are the main findings and proposals in previous research related to product development capabilities in industry to address the three mega-trends: digitalization, sustainability, and servitization; see Figure 1. These findings were then used to compare with and complement findings from the interview studies.

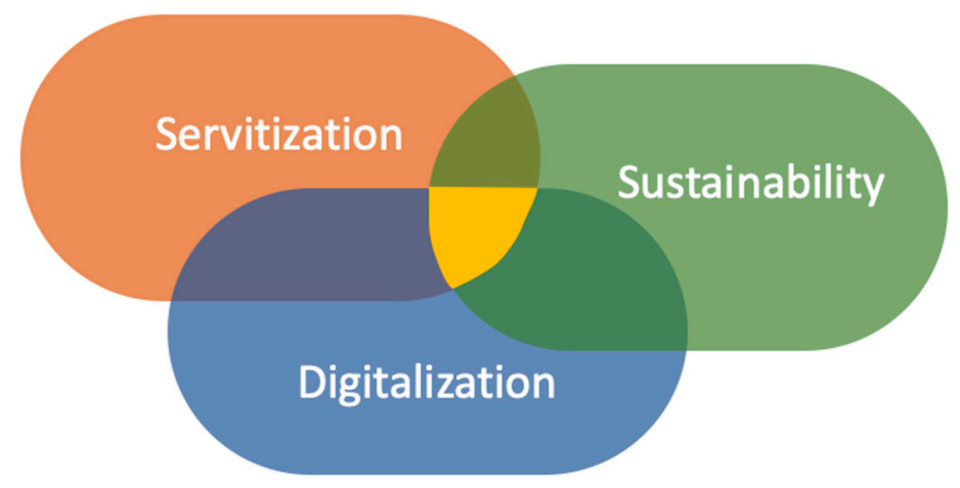

Figure 1. The literature review had the purpose to synthesize and gain new perspectives of the combined subjects of digitalization, sustainability, and servitization, related to manufacturing companies.

Before conducting the systematic literature review, a first investigation using Google Scholar including both journals, conference proceedings and reports showed that this combined area is rather new and few publications on the topic are found before 2010; see Figure 2. The diagram in Figure 2 shows the total number of publications found per year since 2000, when combining the key words "digital" and "sustainable" and "circular" and "servitization" or "servitisation" using Google Scholar (July 2020). The interest in understanding the combined effects of these areas seems to increase according to the number of publications during 2018 to 2019 , which comprise $62 \%$ of the total number of publications (2020 omitted). 


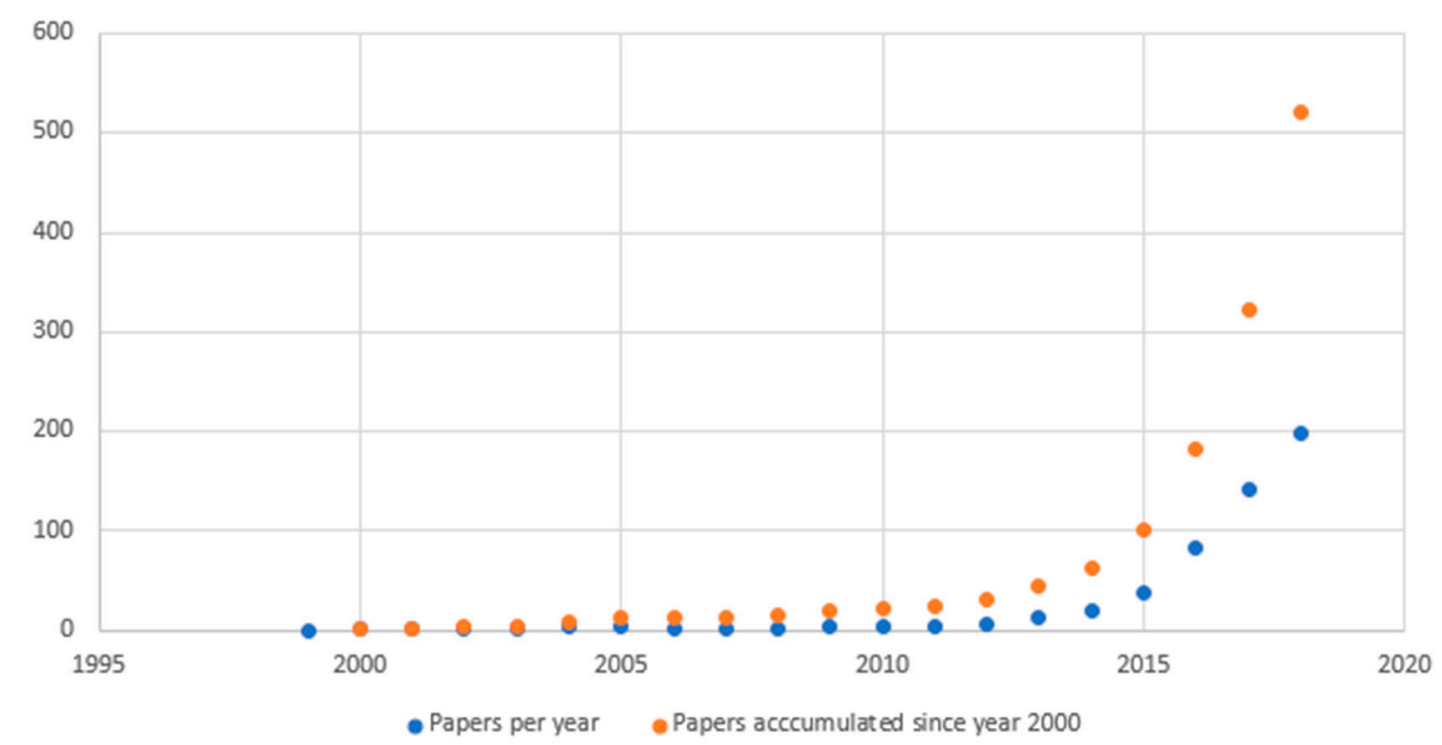

Figure 2. Number of papers since 1995 combining digitalization, sustainability, and servitization from the first investigation using Google Scholar.

For the process of the systematic review, the SCOPUS database was used to find journal publications from January 2007 to April 2020. After an initial search in both Web of Science and SCOPUS, it was concluded that one of the databases would be sufficient to use as they provided same or similar results for the search strings and search limitations. The SCOPUS database was then selected as it is acknowledged to be the largest abstract and citation database of peer-reviewed literature and covers research from multidisciplinary fields. The following of search strings in Table 1, with certain key words (sustainability, digitalization, PSS, servitization, circularity, information technologies) and synonyms to these, were used to identify relevant review or journal articles using SCOPUS. This exploratory review resulted in an overview of the main publications, having these words in the title, the abstract or as keywords; see Table 1.

Table 1. An overview of the search strings and number of publications for each search string.

\begin{tabular}{cc}
\hline Search Strings Used & Number of Publications (Including Duplicates) \\
\hline Sustain * AND Digital * AND PSS & 11 \\
Sustain * AND digital* AND serviti * & $6(10)$ \\
Sustain * AND Serviti * AND Digit * AND circular* & $0(3)$ \\
Sustain * AND It AND serviti * & $27(30)$ \\
After sorting and excluding duplicates & $44(54)$ \\
\hline
\end{tabular}

The review process was then complemented with a structured review and selection process of the papers, in alignment with Popay et al. [44], with the aim to find answers to the following review questions: which challenges and opportunities arise from digitalization; are there any new and enhanced capabilities for digitally aided design tools and methods; how have sustainability aspects been integrated in products, services and processes; how do manufacturing companies find different strategies in society's transitional change towards sustainability, how have PSS aspects been integrated in product development work, and what are some potentials in the industry to combine digitalization with PSS and SPD for innovative and valuable solutions? These review questions were used for the down-selection of papers in the review process.

The most relevant publications in relation to these questions above were reviewed and are discussed in Section 4. The review started with the reading of the title, abstract, and conclusions. Further, a full paper screening was conducted, adding introduction, results, and finally background, objectives, and setup [45]. 
The use of snowballing techniques, i.e., a study of "references to references" [46], added up to the total number of 31 articles in the review. Figure 3 shows the paper search and down-selection process. A record and a worksheet were created, including a summary of each reviewed publication alongside other key attributes, e.g., publication year, degree of relevance, and a comment on which of the three areas the publication addressed.

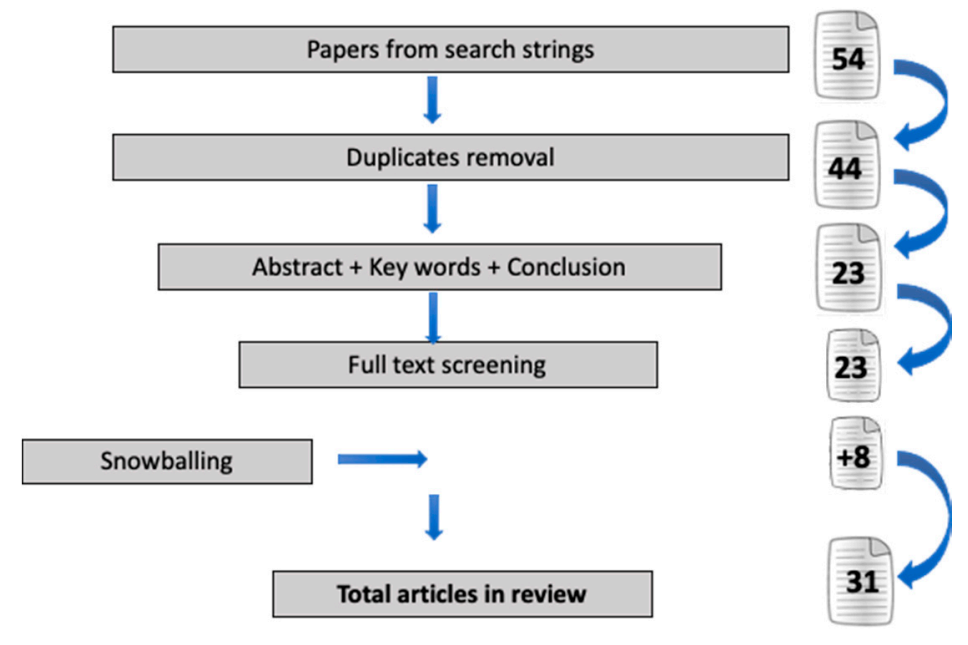

Figure 3. The result from the structured review and selection process.

\subsection{Interview Study and Selection of Companies}

The main purpose of the interview study was to investigate and give a view on what possibilities and challenges companies perceive today with respect to the mega-trends and, more specifically, how these trends and means impact the product design and product development capabilities in companies. The industries selected for this study are all Swedish-based manufacturing companies representing the industry sectors of transportation and logistics, and machinery and equipment. They develop and produce products and some also offer product-service solutions. The selection of the companies was motivated by the expectation of these sectors being in a transition phase driven by sustainability, servitization, and digitalization of their processes and products. The selected companies are business-to-business companies that develop-and sell-advanced and complex products. Their technology, business, and collaboration with customer and suppliers are possibly affected by changes due to these trends, which was one of the company selection criteria. The group of selected companies were broad in the sense that they covered: (i) small, medium-sized, and large companies, (ii) original equipment manufacturers (OEM), and (iii) component and sub-system manufacturers. Eight different companies were selected and one to two experienced persons in each company were selected for the interviews. The roles selected for the interviews were R\&D managers or business development managers, project leaders with an engineering role or design leaders and specialists for technical development. In the small firms, the managing director was interviewed covering these roles.

Company $\mathrm{A}$ is a manufacturer of machinery and equipment for forest and garden solutions with about 8700 employees, companies B and C manufacture products and provide services in the construction industry and transportation domain as OEMs with about 4000 and 2000 employees respectively, and Company $\mathrm{D}$ is a vehicle manufacturer with about 900 employees. These four companies are all considered to be large companies. Company $\mathrm{E}$ is within the construction industry, and company $\mathrm{F}$ is a manufacturer of sealing solutions for cables and pipes. Both are medium-sized companies with about 300 employees. Company $\mathrm{G}$ and $\mathrm{H}$ within the area of machinery and equipment are small product-owning companies with about 20 employees. See Table 2 for details of the companies and interviewees involved in the study. 
Table 2. Case companies in the interview study representing different industry sectors.

\begin{tabular}{|c|c|c|c|c|c|c|}
\hline Company & $\begin{array}{l}\text { Business } \\
\text { Sector }\end{array}$ & Company Product & $\begin{array}{l}\text { Number of } \\
\text { Employees }\end{array}$ & $\begin{array}{c}\text { Yearly } \\
\text { Turn Over }\end{array}$ & Interviewee & $\begin{array}{l}\text { Gender/Years at } \\
\text { the Company }\end{array}$ \\
\hline A & $\begin{array}{l}\text { Machinery and } \\
\text { equipment }\end{array}$ & $\begin{array}{l}\text { Machinery and } \\
\text { equipment for forest } \\
\text { and garden solutions }\end{array}$ & 8700 & 39 billion & $\begin{array}{l}\text { (i) Global R\&D responsible and } \\
\text { (ii) Global director for master } \\
\text { data management }\end{array}$ & $\begin{array}{l}\text { (i) Male/3 } \\
\text { (ii) Male/4 }\end{array}$ \\
\hline B & $\begin{array}{l}\text { Transportation } \\
\text { and logistics }\end{array}$ & $\begin{array}{l}\text { Machinery for the } \\
\text { construction industry }\end{array}$ & 3500 & 39 billion & $\begin{array}{l}\text { (i) Globally responsible for a } \\
\text { business platform, (ii) System } \\
\text { responsible in service systems }\end{array}$ & $\begin{array}{l}\text { (i) Male/16 } \\
\text { (ii) Female/1.5 }\end{array}$ \\
\hline $\mathrm{C}$ & $\begin{array}{l}\text { Transportation } \\
\text { and logistics }\end{array}$ & $\begin{array}{l}\text { Aerospace } \\
\text { components }\end{array}$ & 2000 & 7.8 billion & $\begin{array}{l}\text { (i) Chief Technologist, } \\
\text { (ii) Technology Lead of } \\
\text { component group }\end{array}$ & $\begin{array}{l}\text { (i) Male/31 } \\
\text { (ii) Male/26 }\end{array}$ \\
\hline $\mathrm{D}$ & $\begin{array}{c}\text { Transportation } \\
\text { and logistics }\end{array}$ & Large vehicles & 900 & 9.9 billion & $\begin{array}{l}\text { (i) Responsible, product } \\
\text { development process }\end{array}$ & (i) Male/12 \\
\hline E & $\begin{array}{l}\text { Transportation } \\
\text { and logistics }\end{array}$ & $\begin{array}{l}\text { Machinery for the } \\
\text { construction industry }\end{array}$ & 335 & 1 billion & $\begin{array}{l}\text { (i) Project leader of digital } \\
\text { solutions, } \\
\text { (ii) Team leader for system } \\
\text { development }\end{array}$ & $\begin{array}{l}\text { (i) Male } / 3,5 \\
\text { (ii) Male/16 }\end{array}$ \\
\hline $\mathrm{F}$ & $\begin{array}{l}\text { Machinery and } \\
\text { equipment }\end{array}$ & $\begin{array}{l}\text { Sealing solutions for } \\
\text { cables and pipes }\end{array}$ & 248 & 1 billion & $\begin{array}{l}\text { (i) Executive Vice President for } \\
\text { product development, } \\
\text { (ii) Manager for product } \\
\text { development and engineering }\end{array}$ & $\begin{array}{l}\text { (i) Male } / 3.5 \\
\text { (ii) Male/10 }\end{array}$ \\
\hline G & $\begin{array}{l}\text { Machinery and } \\
\text { equipment }\end{array}$ & Warehouse Trucks & 28 & 0.60 billion & $\begin{array}{l}\text { (i) Managing director (owner) } \\
\text { (ii) Head technology } \\
\text { development/designer }\end{array}$ & $\begin{array}{l}\text { (i) Male/20 } \\
\text { (ii) Male/10 }\end{array}$ \\
\hline $\mathrm{H}$ & $\begin{array}{l}\text { Machinery and } \\
\text { equipment }\end{array}$ & $\begin{array}{l}\text { Remotely operated } \\
\text { vehicle systems }\end{array}$ & 8 & 0.10 billion & $\begin{array}{l}\text { (i) Managing director (owner) } \\
\text { (ii) Head technology } \\
\text { development/designer }\end{array}$ & $\begin{array}{l}\text { (i) Male/20 } \\
\text { (ii) Male/7 }\end{array}$ \\
\hline
\end{tabular}

One of the authors was present for each interview, and an audio recording was made for each interview. After a short introduction to the mega-trends, the interviews were guided by a set of semi-structured interview questions divided into three blocks of open questions, around eight in total; see Appendix A. The result was analyzed using a thematic analysis approach [47].

\section{Results from Literature Review}

There is a clear increased research interest from the last three years on these three trends in combination (see Figure 2), based on the number of articles, including also conference publications, during the latest 10 years. New concepts and definitions are proposed in several publications, e.g., Digital Servitization [48] and Sustainable Smart Manufacturing [49], indicating a research field with potentials for explorations and development.

In previous research, several studies have focused on review studies rather than surveys and cases from the industry. The papers returned as an output from the literature search were published in sustainability-, informatics- and management-oriented journals showing a clear lack of studies combining these three fields from engineering-oriented journals; see Table 3. In addition, a majority of the studies presented analyses and proposals for business model development in the transition towards a circular or digital business, e.g., [50-54]. Even if it is stated in the literature that companies need many different capabilities in the transformation to meet the three new trends, such as operational capabilities, dynamic capabilities, strategic capabilities, net-work capabilities, and service innovation capabilities [50], the discussion on new product design capabilities to meet these three trends is under-represented. 
Table 3. A majority of the papers found from the literature search were published in sustainability-, informatics, and management-oriented journals. Most were review studies.

\begin{tabular}{|c|c|c|c|c|c|}
\hline Journal & $\begin{array}{l}\text { Number of } \\
\text { Articles }\end{array}$ & $\begin{array}{l}\text { Review } \\
\text { Studies }\end{array}$ & $\begin{array}{l}\text { Survey/Case } \\
\text { Studies }\end{array}$ & $\begin{array}{l}\text { Analysis of } \\
\text { Cases/Data }\end{array}$ & $\begin{array}{c}\text { Literature Review, Case } \\
\text { and/or Prescriptive Study }\end{array}$ \\
\hline J. Cleaner Production & 3 & 3 & & & \\
\hline Sustainability & 6 & 3 & 1 & 1 & 1 \\
\hline $\begin{array}{l}\text { Journal of Computing and Information } \\
\text { Science in Engineering }\end{array}$ & 1 & & & & 1 \\
\hline Asia Pacific Journal of Information Systems & 1 & & & & 1 \\
\hline Advanced Engineering Informatics & 2 & 1 & & & 1 \\
\hline California Management Review & 1 & & & & 1 \\
\hline J. Business Research & 1 & 1 & & & \\
\hline Management Review Quarterly & 1 & 1 & & & \\
\hline $\begin{array}{l}\text { International Entrepreneurship and } \\
\text { Management Journal }\end{array}$ & 1 & 1 & & & \\
\hline $\begin{array}{c}\text { Journal of Enterprise Information } \\
\text { Management }\end{array}$ & 1 & 1 & & & \\
\hline Int. J. Production Economics & 1 & & & 1 & \\
\hline Service Management & 1 & 1 & & & \\
\hline Operations Management research & 1 & & 1 & & \\
\hline RECIEL (Wiley) & 1 & & & 1 & \\
\hline \multirow{2}{*}{ Rivista di Studi sulla Sostenibilita } & 1 & & 1 & & \\
\hline & & 12 & 3 & 3 & 5 \\
\hline
\end{tabular}

Sustainability, digitalization, and servitization are connected in several ways described by different authors; see Figure 4. In general, this means that servitization is seen as PSS solutions and PSS can be viewed as the result of servitization [55]. Servitization is not a new concept at all. It was defined in the late 1980s by Vandermerwe and Rada [56] (p. 314) as "the increasing offering of fuller market packages or bundles of customer focused combination of goods, services, support, self-service and knowledge in order to add value to core corporate offerings." Since then, the PSS concept has emerged and both servitization and PSS are based on the premise that manufacturing companies are selling integrated product -and service solutions. In Szász and Seer [57], servitization is referred to as "the transition process of manufacturing firms from exclusively selling products to their customers towards offering more complex value propositions including both product and service elements." In a systematic literature review study on the topic of the purchasing of business services by Hoffman et al. [58], it was concluded that servitization now has become a critical part of competitive advantage and that it is an important source for profit in many companies. This is also stated in Szász and Seer [57], who conclude that services are harder to imitate. Service innovation can therefore become crucial for companies in the future, making it important to have a service strategy at the company as an integral part of the operations strategy of a manufacturing company. In addition to this, there is a need to explore how service purchasing can contribute to both environmental and social sustainability as sustainability has not received much attention in business purchasing literature yet. This might, however, change with the circular economy. According to Hojnik [59], studies indicate that servitization will play a major role in the circular economy and result in resource savings and more efficient usage of products. To address society's challenges, service operations is pointed out as one of eight promising research themes for innovative work in a review study by Victorino et al. [60]. To support the transition to a more resource-efficient society, thus promoting sustainability, the European Commission proposed a Circular Economy package 2016 [59]. Other means of control from the EU where servitization and sustainability come together are the Ecodesign Directive that, for example, emphasizes the durability of products; the Energy Efficiency Directive that, for example, promotes the selling of energy services to all final customers; the Policy on waste management with, for example, the extended producer responsibility, and taxes where there are four different taxes categories (energy, transportation, pollution, and resources). According to Szász and Seer [57], it is a viable path for companies to choose servitization as a strategic direction, if it is based on a deliberate, structured, and strategic thinking to meet increased stakeholder pressures of sustainability performance. Further, these authors argue that 
product-oriented service will not lead to higher sustainability performance. Instead, customer support services, including use-oriented and result-oriented services, should be selected for that purpose.

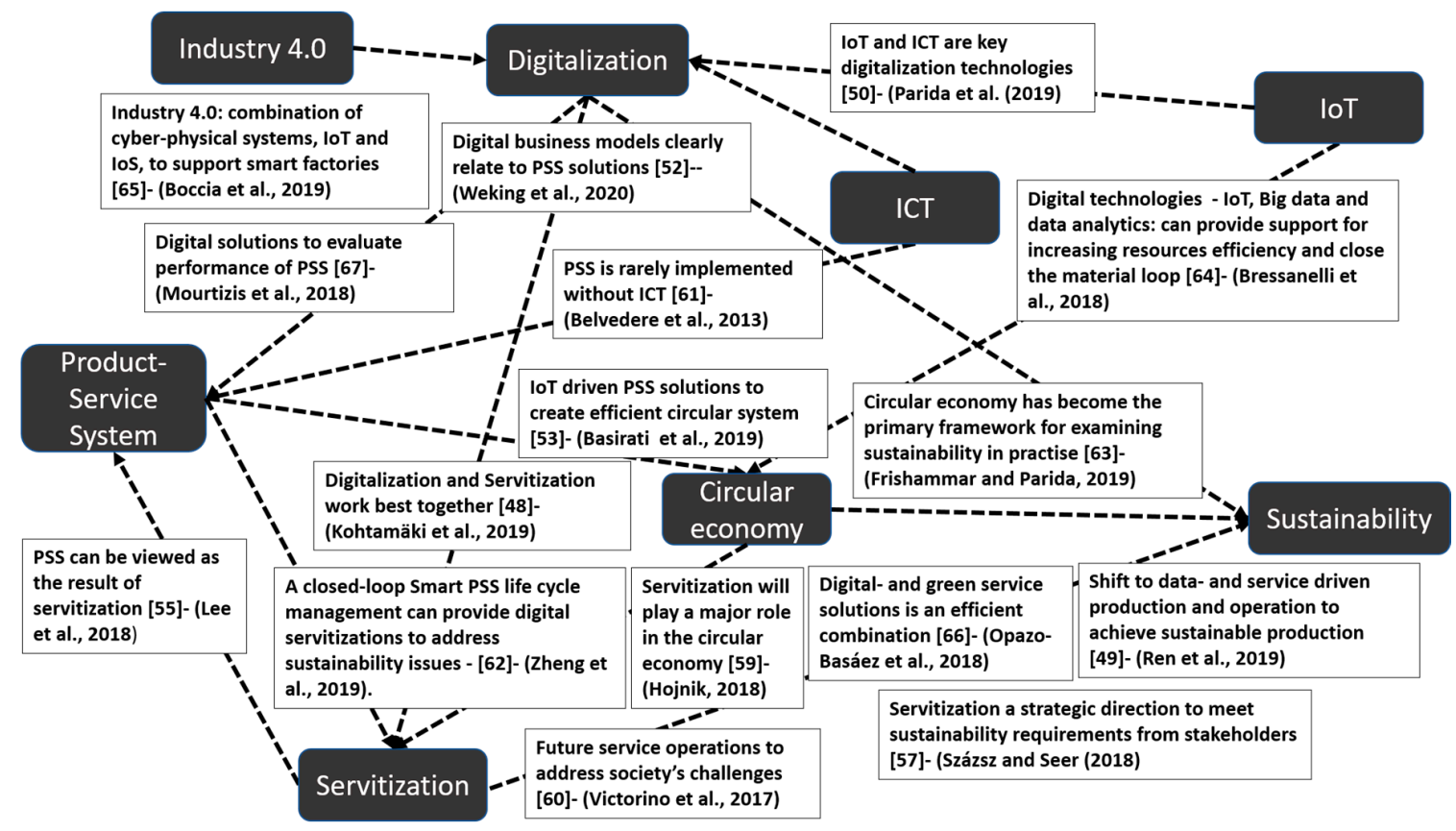

Figure 4. Connections between digitalization, servitization, and sustainability, based on the literature review [48-50,52,53,55,57,59-67].

The literature also states that digitalization and servitization work best together [48] and PSS are rarely implemented without ICT, according to Belvedere et al. [61]. In line with this, Zheng et al. [62] present results from a systematic review of smart PSS, which includes IoT-enabled PSS and Cyber-physical systems. Their study shows that Smart PSS should be conducted in a data-driven platform-based approach using disruptive technologies with context awareness. Furthermore, for the circular economy, a closed-loop Smart PSS life-cycle management can provide exclusive types of digital servitizations to solve societal challenges and to address sustainability issues. To examine sustainability in practice, the circular economy has become the primary framework [63] and several researchers state that servitization will play a major role in the circular economy and in meeting society's challenges and stakeholders' sustainability requirements $[57,59,60]$. Therefore, to create efficient circular systems with increased resource efficiency and to close the material loop, the usage of digital technologies, e.g., IoT, big data and data analytic, or IoT-driven PSS solutions, are needed [53,64]. To create these new digitalized services or PSS solutions, there are different types of business models [52]. However, there is a lack of guidance for business model development and, therefore, Frishammar and Parida [63] propose a step-by step roadmap support in turning linear business models into circular models. Further, they state that their framework is a tool to manage risk and uncertainty as it allows firms to better understand what circular transformation can look like. In the future, it is expected that many companies end up managing a portfolio of business models rather than a single model.

The review showed that there are several benefits for companies in adoptions of digitalization or application of digital service solutions, e.g., improved cost efficiency due to improved internal processes, new or increased revenue streams often based on PSS solutions, new risk management approaches with increased transparency by providing real-time data insights, reduced production costs, improved productivity, more detailed information about production cycles, coordinated operations, the enabling of resources allocation, optimized deliverables, improved product design, and attracted target customers. In addition to that, it opens up possibilities to better monitor and track products' activities during the complete life-cycle, optimize the product usage, upgrade the product, enhance renovation and end-of 
life activity, as well as to provide improved technical support with preventive maintenance $[49,64,65]$. Indirectly, sustainability benefits can be obtained from digitalization, such as improvements in efficiency and product design, extension of the product lifespan, predictive maintenance, manufacturing efficiencies through material flow management, increased safety as dangerous jobs are replaced with knowledge-intensive tasks, and the closing of the material loop $[49,64,65]$. There are many business benefits with digital solutions and a study conducted by Opazo-Basáez et al. [66] concludes that it is beneficial to have a digitalized service offering first, and then add a green service to that with the aim to offer a more sustainable solution, in comparison to having a green service stand alone. For example, if the aim is to increase circularity of resources through repair, remanufacture, and recycling, a digital service can enhance the resource management in operation.

Even if there are many benefits in adoptions of digitalization, there are also challenges that are not emphasized or even mentioned in some of the previous studies. Many of these challenges need to be solved before entering into a new business model, such as how to solve the ownership of data and their use, how to deal with the investment costs and, for smaller companies, how to compete with large companies that can invest in the new technology at a higher pace [65].

There are, thus, both pros and cons with smart PSS, e.g., pros: reduced energy consumption by responses to customer behavior in real time; cons: privacy loss, or social discrepancies. Liu et al. [68] therefore propose a method to particularly evaluate the sustainability of smart PSS and suggest how to weight the different sustainability criteria in such a method. Kwok et al. [69] also discuss how to give weighting to different sustainability criteria in support tools for sustainability assessment in early design phases. However, which of and how the sustainability criteria are selected in the first place is even more important as the evaluation will be of less value or even misleading if the correct sustainability criteria are not selected. There are different approaches between the method suggested by Liu et al. [68] and the method proposed by Kwok et al. [69]. Liu et al. [68] use a few criteria covering all three dimensions of sustainability, i.e., the social, economic, and ecological dimensions, and a PSS life-cycle on an overall level. Kwok et al. [69] include socio-ecological sustainability indicators covering a product life-cycle, which are derived systematically from a product sustainability design space [70]. This approach has its strength in that it is based on a backcasting approach from scientific scrutinized overarching sustainability principles [27], in comparison to other models that have criteria identified from a forecasting and ad hoc approach, e.g., suggested in Bertoni [71].

As mentioned earlier, companies need many different capabilities in the transformation to meet the three new trends [50] such as operational capabilities, dynamic capabilities, strategic capabilities, network capabilities, and service innovation capabilities. In line with this, we argue that, to increase the competitive capabilities of manufacturing companies, we need to understand their current capabilities to reach higher service performance, sustainability performance, and digitalization performance. We set out to investigate this and the results of an in-depth interview study of eight companies are presented in the section below.

\section{Results from the Interview Study}

This section presents the results from the interview study carried out at eight Swedish-based case companies regarding their perceived potentials in industry to combine the three areas of digitalization, servitization, and sustainability in order to develop innovative and valuable solutions. The results section follows the interview questions in Appendix A and indicates how the manufacturing industry capabilities for product development are affected by these three trends in society.

\subsection{Expected Potentials for Manufacturing Companies in Relation to the Three Trends}

It was an agreement among the interviewees that there are potentials in combining all three areas. Digitalization was, however, expressed as a must in the companies and an opportunity to find new solutions, to meet customer needs and to be competitive on the future market. Digitalization was also pointed out as an opportunity to collaborate in a new way in the value chain and connect directly to 
customers, a way to get access to specific data, make the internal product development work more efficiently, educate and have digitalized instructions to customers, optimize the development or even to learn more about the machines that were developed, and to minimize waste through simulations.

"Digitalization is a prerequisite for being a strong player. To be able to offer subsystems and modules in the future-our company needs to increase the digitization part even more." Company C, Technology Lead of component group.

Companies (e.g., company A) working directly with societal customers, such as cities, see digitalization already as a fundamental mechanism to understand customer needs and develop their solutions to match these needs. Typically, such solutions are based on digitalized data, provided as services and a tailoring of a mixed hardware and software offering. Digital twins, autonomous electrical machines, or co-pilots can all be seen as solutions with a combination of these three areas, as a digitalized service solution was considered to be beneficial from a sustainability point of view. As one of the interviewees phrased it: "The main target is to do more sustainable solutions and to do that PSS can be used." Company B, System responsible in service systems.

These digitalized service solutions have a clear customer value, e.g., customized solutions dependent on usage patterns, optimized maintenance programs and reparation only when needed, possibility for the user to optimize the usage of the machine, and the possibility to have a cleaner environment and to operate from a distance. Through digitalization, companies both get a new and direct communication with end customers, leading to a much more specific information of the use of products. Several interviewees stated that benefits from these data currently drive the development of new business models, but the area of how to use these benefits for new product development is still in its infancy.

\subsection{Company Focus and Interests Regarding the Three Areas}

The study showed that digitalization is prioritized and the interest has increased the last three years in all interviewed companies. The difference is that the OEMs focus and combine digitalization with PSS, while the component supplier company has focused on using digitalization in their internal development processes to optimize and make the process more efficient. One of the small firms, with inhouse production, also mentions the ambition of using digital (or Industry 4.0) solutions for more efficient production, such as human robot interaction (so called cobots), to improve ergonomics and precision in manufacturing operations. Another company integrates digitalization systematically and measures the progression to keep up the pace. As one of the interviewees said: "...we measure ourselves within five areas-we have a digital base from which we decide about strategic goals and evaluate where we are within 5 years-digital products and usage of data are two of those five areas." Company F, Executive Vice President for product development.

In general, sustainability aspects have a higher priority during the latest years in the companies due to both regulatory and customer requirements. With other words, it is mainly about keeping sustainability on a level where the technical and legislation requirements or expectations are met. However, a more proactive approach was described in one of the larger OEM companies (company D) where they have a dialogue and interaction directly with cities as customers. This has led to recognition of innovations to deal with, e.g., health issues and quality of living. The medium-sized companies (company E) do not prioritize sustainability as highly when the requirements of sustainability from customers are weak. Further, only when the customers clearly articulate needs for more sustainable solutions for their operations, does the focus of the small-sized manufacturers shift. "...customers need to require a more sustainable solution and for that to happen legislation and societal initiatives are needed." Company E, project leader of digital solutions.

The medium-sized companies (companies E and F), however, showed a willingness to develop and be proactive instead of being reactive, waiting for external push or requirements. In one of the medium-sized companies (Company F), there were several examples of stepwise improvements of the product life-cycle, driven by either customer requirements, future customer goals, or own ambitions. 
How to prove if a more sustainable solution is offered, was considered unclear. Some of the interviewees assumed that an improvement in one of the life-cycle phases meant a more sustainable solution. While other companies, e.g., company C, meant that to be certain of a sustainable solution, it has to be supported somehow, for example, by using defined sustainability criteria, or from measuring sustainability indicators. The uncertainty of environmental risk and long-term consequences was one reason as to why the small companies kept a careful approach, i.e., not changing to new materials and equipment that might give a reduced sustainability impact.

Several manufacturers agree that the digitalized solutions developed for their product naturally are combined with a PSS model, and one interviewee emphasized the need to build digitalized solutions that have a tight link to their product- and process knowledge, to avoid being copied by competitors. As the suppliers have less opportunities to provide PSS solutions, the interest has been weak in the supplier company (e.g., Company C). There may therefore be a risk that the component supplier company will lose market opportunities as many new digitalized solutions offered on the market are service-oriented. This readiness is clearly expressed by one of the small firms; although it cannot lead the development of PSS in its field of business, it is attentive in regard to being able to provide requested services through its re-selling network and partners. "Before, it was all about product requirements such as higher speed and lifting capacity. Today it is about safety and energy efficiency. For example, battery capacity and the driver's interface and ergonomics. There is a trend towards PSS but we have not come that far yet, other than training and some after-market services." Company G, Head technology developer/designer.

One OEM (company D) identified an emerging need to build tight and strategic relations with suppliers in order to integrate effectively new technologies as technology is being developed on a subsystem level, and integrators need to understand how to utilize new technologies. The other reason was the insight that they need to focus much more on understanding their customers' underlying needs and cannot keep the necessary expertise in-house for all critical technology domains.

\subsection{Future Perceived Changes in Product Development}

Our study showed that digitalization will gradually change the working process. More data need to be analyzed and several sources and types of data need to be analyzed at the same time. To be a strong player in the future, the efforts in integrating digitalization are important. New solutions are expected to meet the future needs, and new competences and skills are needed. For example, there will be a need for engineers that can do programming, create new platforms, develop new software, and understand new business models. At least, the engineers need to be able to apply new digital technologies. It is necessary for manufacturing companies to uniquely identify their individual products to enable many of the envisioned services for their business offers. The establishment of a master data structure is at the heart of the manufacturers business, something that requires a change in established practices.

The time aspect differs between digitalized solutions and physical artifacts with associated services such as maintenance and training. Digitalized solutions need to be exchanged more frequently than traditional product life-cycles today, especially compared with physical products that have longer life-cycles. Digital (software) solutions are also developed with much higher iteration frequency than hardware solutions, and a challenge for product development is to combine the "traditional" product development of hardware-dominated products with a continuously increasing electronics and software content.

Our empirical results show that sustainability has an influence on the decisions and the solutions that are generated and offered on the market, even if there is a difference in the companies' sustainability priority. One of the medium-sized companies indicated a reactive change and the other medium-sized company indicated a proactive change in product development. "Now we have to change and look at new requirements for particle filtering. Enormous amount of our engineering capacity and resources 
goes into that right now. It is a legal requirement we need to fulfil" Company E, project leader of digital solutions.

"Due to customer requirements, we have already had to look into new materials. We do study alternatives in a higher speed than before" Company F, Manager for product development and engineering.

All interviewees agreed that awareness, understanding, and some on-going learning are needed in this field to be able to be proactive. Sustainability integration is an obvious challenge in the future and there is a need to be proactive in order to keep the solution freedom and not have to adapt to even more regulations and restrictions.

\subsection{Product Development Capabilities Influenced by the Three Trends}

There has been new learnings and new approaches in the development and design of new products and production systems due to real-data information (digitalization). Instead of an instant change, it has come gradually. For example, new solutions when data is transferred between different machines require more advanced computers. The increased software content in products and services is already influencing the product development work practice. For example, virtual testing and 3D printing is more common now and has become a more natural part of the development than before. Agile methodologies that have been prevalent in the software industries over more than a decade are now introduced also in equipment manufacturers' development processes. The product development process also needs to find new ways of harmonizing software development with hardware development, where the development cycle is quite different in the latter. "We have become more agile in our working process." Company F, Team leader for system development.

"We can trace information from certain machines in certain areas during a certain period and look at exact data/models for these machines. This is a fast way to resolve problems of the machines-very fast." Company E, Project leader of digital solutions.

It is not clear how SPD has actually influenced and affected the design process, more than on some additional material checklists. However, SPD is considered to be important and something that is applied increasingly, and conscious choices are needed that require skilled engineers regarding sustainability. At present, the judge is the customer who increasingly values and evaluates sustainability aspects, something that most companies are well aware of. The processes for developing sustainable products is less well understood.

PSS is largely seen as a new business model, although insights exist in regard to the decisive need to combine product knowledge with the business model. With the access to digital data, new services can be offered to customers to optimize service and maintenance as well as to optimize performance of the machine. These digitized PSS solutions will offer a better sustainability profile as well. However, there are no support tools in the studied companies that are used to explore and visualize this combined benefit.

\subsection{Challenges for Realizing the Potentials of Digitalization, SPD and PSS in Industry}

A clear barrier for expanding in the digitalization field is the lack of competence and resources in terms of money for development and investments. According to one of the interviewees: "Availability of skilled people is decreasing throughout the world. The groups of people that have these skills are not growing as fast as the need at the market. Lack of skills is a hinder. The skills are a unique combination of a professional programmer but not extremely skilled. You need to be very good at statistics and analysis and specific application knowledge. Then you can do more-because you can see what is possible." Company E, Project leader of digital solutions.

There is a risk that top managers do not have the awareness and competence in the field of digitalization and, therefore, they do not see the potentials, nor do they make the necessary priorities. Another challenge mentioned by the interviewees is the change into a more agile approach. In order to keep up with the development potentials in the area of digitalization, new collaboration forms are 
needed or, instead, the purchase of competences and key businesses that already have the right competence that can develop solutions. A major challenge is also to have the ability to invest in the introduction of novel, disruptive technologies while keeping efficiency in "classical" product offers.

Other challenges related to digitalization are intellectual property rights and how to collaborate around data, revolving around questions such as: Who owns the data? Can a new business model be created based on imported data? How to deal with the increased exposure of data raises questions on cybersecurity. Answers to these questions are not solved and in a long value chain it can delay the development.

For the SPD area, an internal company priority is to focus more on sustainability aspects. To make it become a selling point, it needs to be connected with a customer need that impacts some key requirements, e.g., safety issues. Some sustainability indicators need to be selected and then continuously monitored. According to the small company, as a manufacturer, they need to see the value of doing more sustainable solutions. Also, awareness, dissemination, and internal communication are important to expand in this area. There is a need for champions that lead the area and that have a position in which they can influence decisions. However, some interviewees see the importance to make everyone responsible at the company and find an efficient way to connect and collaborate in the sustainability area. Increased competences and support tools are needed to understand how to get an answer to new questions that are related to sustainability, according to an interviewee at one of the medium-sized companies. It is specifically challenging to integrate sustainability for the companies that sell to less sustainability-driven customers. As one of the interviewees phrased it: "Customers seem to select more sustainable solutions if they are forced to by legal requirements or if they can make more money out of it. Totally dependent on the requirements that are set by society to make big changes here. Social media can suddenly draw attention to what is happening. But as long as this does not happen, average people is unaware of what happens and the risk for stakeholder reaction is low, and therefore the legal requirements become more important." Company E, Project leader of digital solutions.

Our study showed that PSS also depends on the company's priority and customer needs. If there is a clearly expressed customer need, then a company interest will be developed. Many of the interviewees also stressed the interconnected nature of servitization and digitalization, and the fact that digitalization enables new services. Although examples on applications were brought up, the collective assessment was that these are pilots, still, and the real transition has just started.

\subsection{Beneficial to Combine Digitalization, SPD, and PSS to Meet Future Expectations}

It is clear that it is beneficial to combine the three areas to meet future expectations, even if these trends do not influence the small companies yet: "We currently do not see that these trends have major influence on our way of working today" Company G, CEO. Today there are good examples of how sustainability advantages can be achieved from tracking real-time data during usage phases to avoid extra repairs or to optimize the maintenance. These more resource-efficient and sustainable service-oriented and digitalized solutions are not, however, developed to purposely develop more sustainable solutions. Profitability and customer needs are the drivers. However, there are potentials to deliberately create solutions that could give a company a business advantage and at the same time contribute to a more sustainable society. "If we aim for more sustainable solutions it should be a service connected to the product. There is a possibility to improve soft offers. Digitalization is a tool to develop PSS and keep track on data." Company B, Globally responsible for a business platform.

"Some customer companies have sustainability goals. We can support them in how to meet their goals by providing solutions which will probably be a mixture of PSS and digitalization. "Sustainability will be used as a motivation" Company E, Project leader of digital solutions. 


\section{Discussion}

The purpose of our study was to identify (i) the main findings and proposals in previous research in the combined field of the three product development capabilities of digitalization, SPD, and PSS related to manufacturing companies, and (ii) how manufacturing industry representatives perceive the potential of combining these areas for innovation. The study reported is a combined literature and interview study, with certain limitations. For the literature review, we limited the search to the SCOPUS database after a first trial of searches in both the Web of Science and the first screening study in Google Scholar; see Figure 2. SCOPUS was found to be sufficient for the purpose and it provided a broad coverage of the search topics. For the interviews, we limited the study to eight companies, which is why the results give limited but in-depth results and examples from a range of manufacturing domains, size, and type of companies. Based on the findings in this study, a broader study can be formulated using a questionnaire-based survey. It is noted that sustainability-, informatics-, and management-oriented journals dominated the literature search results, whereas the engineering design journals were not represented. One reason may be the overarching nature of the trend areas, and that engineering design research focuses on more specific aspects and consequences and not on the totality. This indicates that engineering, and engineering design in particular, need to better include contextually complex situations, which is in line with Subrahmanian et al. [2].

\subsection{Capabilities in Product Development for Realizing the Potentials of the Trends}

This study showed a need for new and complemented education in industry on the three areas in order to meet the possibilities, needs, and expectations from society. Therefore, strategic measures from a societal level in offering multidisciplinary education, as well as long-life learning efforts, should be prioritized, as also discussed in Eckert et al. [72]. A higher educational level can both generate new unique solutions and improve the company's internal work processes, and, together with support companies and suppliers, be prepared and more proactive in the transition towards a more digitalized and sustainable society. If the companies are not proactive, there is a risk of jumping from one issue to another without any strategic plan for long-term changes. There were some clear examples in our study where customers (pushed by legislation) set new requirements, where they, for example, abandoned a material or required a lower emission level, which led to an unexpected focus on the new problems instead of being part of a planned change.

Digitalization is "a truly influential trend that must be embraced by companies to ensure future competitiveness" [73], a statement also summarizing the view of the interviewees. How to define digitalization differs some and, in the literature, several definitions are proposed. Based on six different definitions of digitalization, Parida et al. [74] suggested the following definition: "use of digital technologies to innovate a business model and provide new revenue streams and value-producing opportunities in industrial ecosystems," with a focus on how to profit from digitalization. Further, they propose the importance for companies to understand the implications of digitalization for value creation (their offering to customer), value capture (monetary income), and value delivery (strategic partnerships) when developing their new business models. The study shows that there are several questions that need to be answered to make the most out of digitalization. Many of these questions are related to data management. In addition to this, there are other important questions not mentioned by the interviewees, but which are found in the research literature, such as what the data storage and analysis will cost in the future, considering the energy need and sustainability demands related to that [75]. Answers to these questions are not yet found and can delay the development and potentials of digitalization.

In industry, sustainability is often related to the three sustainability dimensions: the economic, ecological, and social dimensions [76]. These three dimensions have a nested interdependency [77], which means that the company cannot be sustainable if the social system and/or the ecological system is not sustainable. It was evident, however, from the interviews that some companies consider the ecological dimension as being separated from the social dimension. Where the social dimension was 
limited to the user phase, the ecological dimension was viewed as the impact from the complete life-cycle of the product. If this is a common view, there are two main issues. Firstly, there is a risk of neglecting social impacts when avoiding ecological impacts, e.g., the shift to a material that is a conflict mineral, and in that way create another sustainability problem instead. There is a risk that a sub-optimization will occur if not all dimensions are taken into consideration at the same time for all life-cycle phases. Secondly, the impact is in focus and there is no sustainable vision of a future solution. This means that there is a risk of only avoiding current impacts, without having a strategic plan towards a more sustainable solution and of developing a flexible platform towards a sustainable vision. Another observation was that few of the companies in this study connect sustainability and PSS with circularity and circular economy. This is in contrast to findings from the literature study, which communicate connections between PSS, circularity, and sustainability $[62,63,78]$, also in combination with digitalization. Our result indicates that there is a lack of understanding of the potentials of these three areas in combination, or at least of how this can be realized in these manufacturing companies.

Servitization refers to "transformation toward a service-dominant logic, which stresses the importance of providing solutions rather than products" [72]. In contrast to findings in literature reviews [57,58], the interviewed companies did not indicate that servitization is a future competitive strategy and an important source of profit, despite the fact that it is less hard to imitate. However, to keep the position on the market, companies need to prioritize service innovation and development as an integral part of their operation strategy. In addition, the challenge of developing business models for servitization was not mentioned as an issue by the companies. However, this topic is central and discussed in several articles, e.g., [48], where new business models are proposed to support companies in the expansion towards digital servitization. If this difference is due to a low maturity level in the companies in terms of servitization, and to the fact that they have not yet realized the challenge of developing new business models, or if the extensive research lately on servitization has resulted in an over-production of business model proposals, can be explored in further studies. However, it is apparent that the PSS approach is critical for manufacturers in the sense that digital offers need to be based on core product knowledge and customer knowledge. Also, the scalability of services is an issue. Examples of an increase in service are found in the after-market service sector in the aerospace industry. Rolls Royce increased their share from $25 \%$ in the beginning of the 1990 s to over $50 \%$ twenty years later [79].

\subsection{Drivers to Develop within the Three Areas}

The reflection on possible changes and company development within these three areas, the result from the literature review, and the interview study indicate that PSS will have a larger portion in future than what we see today. Services will be added more and more. The trend may not, however, be the same for sustainability if there will be the same weak and vague societal demand on sustainability. In that case, the sustainability area will probably not get the same importance in manufacturing companies as digitalization and PSS. It will increase but in a more linear way. What drives a development today is the customers-if they do not ask for it, there is a slow change. This was particularly evident in the interviews with the small companies.

Sustainability is currently driven from the market side. It is the users and the customers that need to take the decision to have more sustainable solutions. At the same time, the industry sees a need for the authorities to express clearly what is required. In a recent study [71], an expert group from the manufacturing industry suggested that business models are established on a national level to accelerate adaption and implementation of more sustainable products and services. In this way, social institutions and industry can meet the future goals together. In addition, common global legislations, incentives, and the nudging of new more sustainable solutions are needed to meet the societal challenges on the future market. As the room of opportunities for companies will decrease over time as long as society is moving in an unsustainable direction [8], a customer-driven approach is probably not enough 
to meet the 17 UN Sustainable Development Goals (SDGs). There are only 10 years to meet the SDGs, and in the report prepared by The Word in 2050 Initiative [20], it is stated that: "the positive changes, e.g., dematerialization, resource efficiency, protection of the global commons, and sustainable behavior, from digitalization will not happen automatically and by itself." On the contrary, there are examples of the opposite and the digital transitions have for examples created greenhouse gas and resource intensive growth patterns. To change this, radical changes are needed to reduce the disruptive potentials of digitalization and to create routes toward sustainability. Even if the European Commission proposed a Circular Economy package in 2016, there are still not many mandatory standards for several aspects of servitization. Therefore, it is important to move from incentives towards mandatory standards to assure a more sustainable industry, according to Hojnik [59].

\subsection{Focus and Ambition of the Studied Companies}

It was evident from our study that the company size matters in terms of different possibilities and approaches that may develop in line with the three trends. The larger companies, A, B, C, and $\mathrm{D}$, had clear strategies and made investments in adapting to a digitalization both in their own development to become more efficient, but also in offering new unique solutions with added values to their stakeholders. Sustainability was seen as a bonus effect of a digitalized or service solution for A, B, and $C$, whereas company D considered sustainability to be their major business driver. The OEMs (A, B, and D) had a clear solution-oriented approach while the supply company, C, focused on their working process and methods used for the development of their technologies and products, regarding digitalization. The specific role that the company has in the value chain seems to have an impact on the approach of the company. This was similar regarding servitization; for the large-sized OEMs, the service solutions were essential while this was not the case for the component supplier.

The medium-sized companies, E and F, were agile, aware, and proactive when it came to digitalization. For example, company E showed a willingness to develop and become better instead of being satisfied with a medium-good level and wait for external push or requirements. This may also have to do with the complexity of the product and the importance of being leaders within the branch. The other medium-sized company, F, showed a proactivity as they regularly measured their digitalization progression. They had also created a service company to be prepared for a change towards more service-oriented solutions, while company E was interested in PSS but had no strategic plan for servitization. Sustainability was not prioritized as highly as digitalization in any of the two medium-sized companies. However, company $\mathrm{F}$ had an increased interest due to sustainability engagement in the management team, whereas company $\mathrm{E}$ had a reluctant approach regarding sustainability, due to weak customer demand.

In the small companies, $\mathrm{G}$ and $\mathrm{H}$, there were no systematic processes nor a formal plan for how to adapt to any of the three areas: digitalization, servitization, and sustainability. Instead, they seemed to have a more ad hoc decision approach regarding development in these areas, dependent on the core team or the owner's values and awareness, and specific or general customer or market demands. One of the small companies, G, explained that they were in the hands of the larger companies on the market, but were actively reflecting on their position in relation to these three trends and how the company can be secured for the future.

Our data, which is based on the responses from the interviewees in the eight companies, are mapped in Figure 5. Based on our study and previous studies [80,81], it seems like the company size, culture, history, and industry play important roles in terms of how fast the companies will develop in relation to the digitalization, sustainability, and servitization trends. 


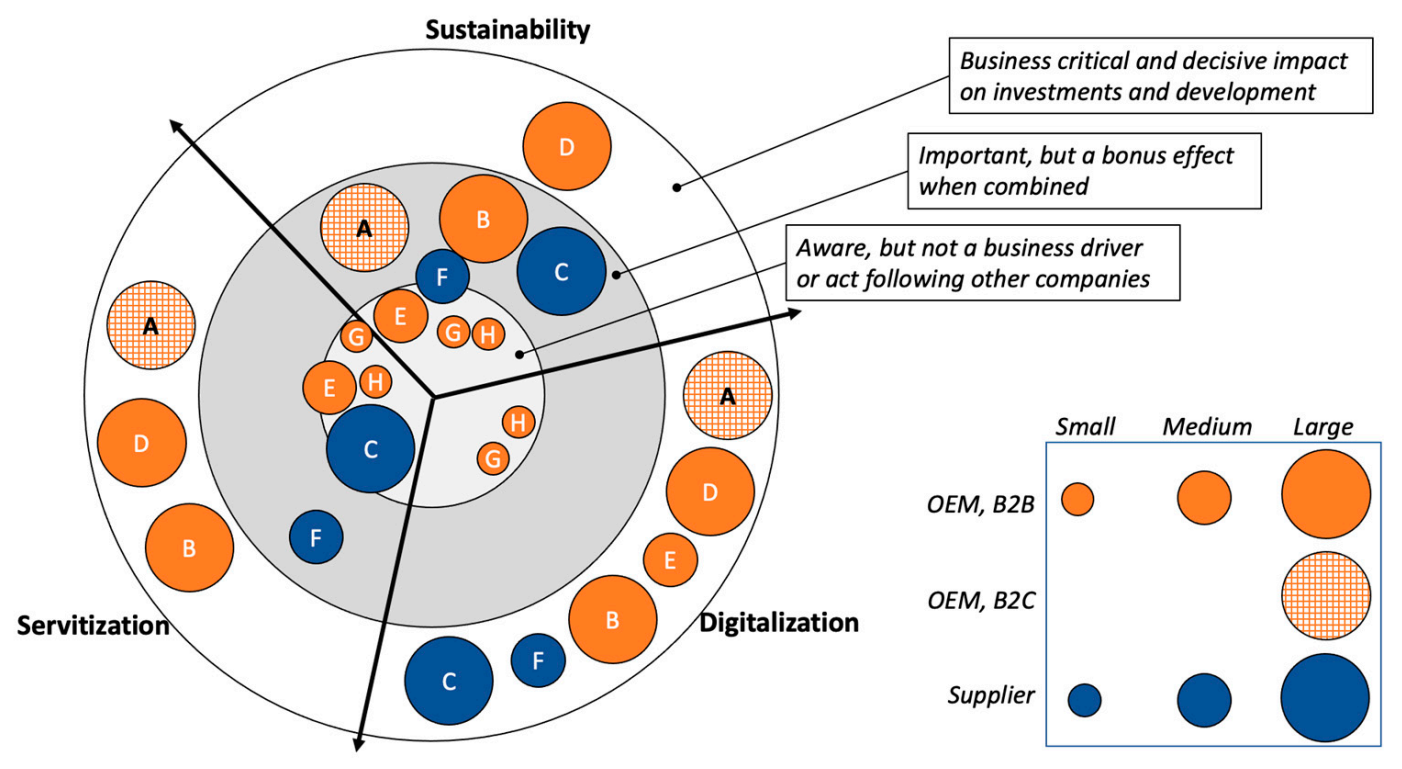

Figure 5. An overview of the focus and ambition of the studied companies.

Regardless of the differences between companies, this study shows that the three areas can be combined advantageously. To make this happen, our suggestion, based on the theoretical and empirical results presented in this paper, is that a common goal and a clear road map is needed and should be developed by the different actors in the value chain. To be a strong player in the future, the efforts in integrating digitalization are important. A clear barrier for expanding in the digitalization field is the lack of competence and resources in terms of money for development and investments. There is a risk that the top managers do not have the awareness and competence in the field and therefore do not see the potentials to make the necessary priorities. Another challenge is the change into a more agile approach. In order to keep up with the development potentials in the area of digitalization, new collaboration forms are needed or the buying of competences or key businesses that already have the right competence and can develop solutions. For the SPD area, it is an internal company priority to focus more on sustainability aspects. To make it become a selling point, it needs to be connected with a customer need, impacting some key requirements, e.g., safety issues, the selection of some indicators, and the monitoring of these. Also, awareness, dissemination, and internal communication are important to expand in this area. Therefore, there is a need to identify more specifically why a digital solution is more sustainable than an alternative solution. If there is a benefit, it can enhance the development and investment of sustainable digital solutions and also inspire further development of these. A company's level of PSS development also depends on the company's priority and customer needs. With a clearly expressed customer need, a company interest will be developed.

\subsection{How to Support the Integration of Digitalization, Sustainability, and Servitization in Product Development?}

The result of this study showed that digitalization will continue to gradually change the working processes in the companies. More data need to be analyzed in the early innovation process and several sources and types of data need to be analyzed at the same time. Sustainability will likely have a stronger influence in the near future on the decisions and the solutions that are generated and offered on the market. Solutions are, for example, expected to be designed for a circular economy [21], and countries, e.g., Sweden, adopt national strategies for implementing Circular Economy [22] that emphasize the importance of the design and development phase. It is a key challenge to make this change and there is a need to be proactive in order to keep the room of opportunities open and not have to limit the possibilities as a result of reactive adaptations without following a strategic plan or vision. 
New solutions (both artifacts and services) that combine digital technologies and services are needed to meet the sustainability challenges. This will require new competences, skills, and development support for how to develop these solutions.

Based on the findings from our study, we propose decision support to be developed to enhance the necessary improvement of design and development capabilities in manufacturing companies. Such support is proposed to include at least four complementary resources: (i) a knowledge management platform including training, skill development, and change management packages; (ii) a platform to enable management and processing of digitalized information; (iii) criteria and metrics measuring the progress and maturation that enable impact assessment; and (iv) support methods and tools to define, model, and evaluate solutions. As an example, a proposed framework, referred to as a Digital Sustainability Implementation Platform (DSIP), includes a knowledge platform that brings together support tools and methods for SPD, PSS, and System Engineering Design in one place to support decision-making on strategic, tactical, and operational organizational levels in the company; see Figure 6. The DSIP data management platform includes features that trace relevant sustainability data tied to product information for each development case. By using such suggested tools, engineers and decision-makers can compare alternative concepts and design solutions in the early stages of product innovation and technology development, based on sustainability measures and other factors, such as cost and customer requirements. This will lead to improved capabilities to innovate and develop solutions, and to increased competitiveness while leading the way towards a more sustainable society.

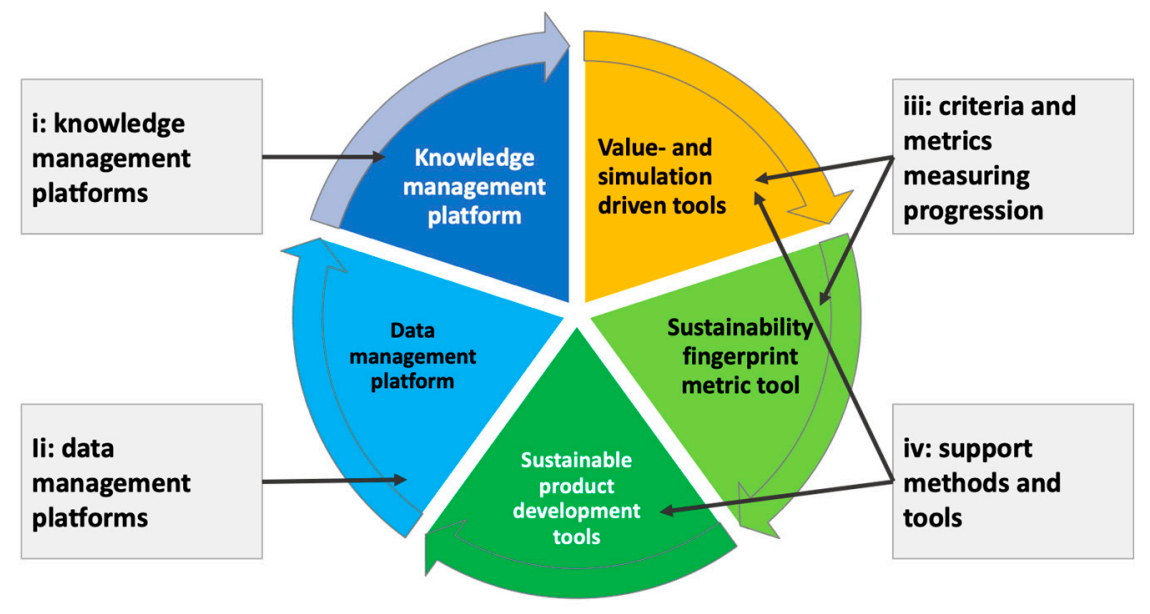

Figure 6. A framework for a digitalized sustainability implementation platform (DSIP) for improved capabilities to innovate and develop solutions while leading the way towards a more sustainable society.

\section{Conclusions and Further Work}

In this study, empirical data showed that digitalization is viewed as an opportunity to find new solutions to meet customer needs, become more efficient, and thereby be competitive in the future market. Further, it showed that the view on sustainability was something primarily done to fulfill requirements and legislation in some companies. Yet, some manufacturers start to see market forces replacing legislation as a sustainability driver. Servitization, finally, was seen as a means to create new solutions and some of the companies chose, rather than are required, to offer PSS solutions. In addition, we conclude that a stronger societal demand for sustainable solutions is needed to prioritize sustainability in product development. Also, to be able to do sustainable product development, use digitalization, and offer product-service system solutions, an increasing effort to offer courses on these topics in engineering education and life-long learning courses for product development practitioners is needed. This seems to be important in order to realize the benefits from combining the three areas and meet future expectations, according to the result from both the literature review and the empirical study. From the literature review, it can be concluded that the three areas are 
intertwined, and that circular economy in combination with digitalization is a key to realize PSS and in meeting society's challenges and stakeholders' sustainability requirements in resource savings and more efficient usage of products. At the same time, there are several other benefits for companies in adoptions of digitalization or application of digital service solutions.

Also, these trends clearly impact the role of the designers that are expected to design entire solutions as opposed to merely artefacts in the future. This implies that designers need to consider not only the product performance and cost, but also the behavior of products and solutions and their impact over complete life-cycles, developed and organized by business networks together with several suppliers and other partners with different capabilities.

Even if it is stated in the literature that companies need many different capabilities in the transformation to meet the three mega-trends, the discussion on new product design capabilities to meet these three trends is under-represented in previous studies. Therefore, our study contributes to the field as this study points clearly to the need for change in product design capabilities as a consequence of the three discussed trends, in a way for individual engineers to master the increased complexity and its interaction with its use context. The main challenge is to empower engineers and development teams to perform this tedious task that encompasses to model, present, evaluate, and develop these expected and smart digitalized solutions in a time-limited environment, and to make prioritization decisions towards the most resource-efficient and sustainable solution.

Based on our study, we therefore propose a novel framework with the purpose of supporting improvements of the design and development capabilities in manufacturing companies to make the most out of digitalization, sustainability, and servitization in industry. This includes to manage data created as a consequence of digitalization initiatives that needs to be securely managed, traced, and made available. Engineers need knowledge and skills for understanding the integration of digitalization, sustainability, and servitization to meet future challenges and design solutions. Furthermore, manufacturing companies need methods and tools to define, integrate, and evaluate solutions, together with a set of necessary criteria that enable management and measurement of the impact of the solutions. In line with this, we propose future studies to focus on design of digital development platforms that support designers' decision making by coherently providing new and evolved capabilities necessary to develop the increasingly complex products and solutions. From this digital sustainability implementation platform, the classical design strategies-with the stages of searching, modeling, simulating, testing and evaluating, refining and detailing of concepts_-and a final, producible and functionally verified product solution definition will be able to address the increasingly complex demand picture and clarify uncertain and unknown long-term consequences. From this platform, complex requirements can be simplified in a convincingly sound manner to secure the future reliability of developed solutions.

Author Contributions: S.I.H., O.I. and A.Ö.R. conceived and designed the research. Literature review was done by S.I.H. Interviews, analysis, and validation were done by S.I.H., O.I. and A.Ö.R. Writing was primarily by S.I.H., and editing and finalizing by S.I.H., O.I. and A.Ö.R. Visualization was done by S.I.H. and O.I. Project administration was done by S.I.H. All authors have read and agreed to the published version of the manuscript.

Funding: A portion of this study was funded by the Knowledge Foundation in Sweden.

Acknowledgments: Sincere thanks to the industrial research partners and the anonymous interviewees.

Conflicts of Interest: The authors declare no conflict of interest.

\section{Appendix A. Semi-Structured Interview Questions}

A Potentials:

A1. What/which possibilities and potentials do you see with:

(i) Digitalization,

(ii) Sustainable Product Development 
(iii) Product-and Service Systems (PSS)

A2. For each of these areas, on a scale 1 to 5, estimate your organization's current engagement, rated from 1 not relevant, to 5 a key area for priorities and investment.

A3. Do you consider that the interest has increased or decreased within the latest 3-4 years within your company for:

(i) Digitalization,

(ii) Sustainable Product Development;

(iii) Product-and Service Systems (PSS). Give examples.

B Impact on product development capabilities:

B1 In which way do you think your organization's ability on product development will be impacted on:

(i) Digitalization,

(ii) Sustainable Product Development;

(iii) Product-and Service Systems (PSS). Give examples.

B2 In which way have your organization's ability on product development already been impacted on:

(i) Digitalization,

(ii) Sustainable Product Development;

(iii) Product-and Service Systems (PSS). Give examples.

C Future challenges:

(C1) What do you think preventing you from realizing your potentials already today? Give examples.

(C2) Can you benefit from combining these three areas to meet future expectations?

C2.1 If yes-and if so, how can you benefit from combining these three areas?

C2.2 If no-why?

\section{References}

1. De Weck, O.L.; Roos, D.; Magee, C.L. Engineering Systems: Meeting Human Needs in a Complex Technological; MIT Press: Cambridge, UK; London, UK, 2011.

2. Subrahmanian, E.; Reich, Y.; Krishnan, S. We Are Not Users: Dialogues, Diversity, and Design; MIT Press: Cambridge, MA, USA, 2020.

3. Oldekop, J.A.; Horner, R.; Hulme, D.; Adhikari, R.; Agarwal, B.; Alford, M.; Bakewell, O.; Banks, N.; Barrientos, S.; Bastia, T.; et al. COVID-19 and the case for global development. World Dev. 2020, 134, 105044. [CrossRef]

4. Köhler, J.; Geels, F.W.; Kern, F.; Markard, J.; Onsongo, E.; Wieczorek, A.; Alkemade, F.; Avelino, F.; Bergek, A.; Boons, F.; et al. An agenda for sustainability transitions research: State of the art and future directions. Environ. Innov. Soc. Transit. 2019, 31, 1-32. [CrossRef]

5. Rolls-Royce. (Holdings Plc,) Annual Report, Strategic Report. Available online: https://www.rolls-royce. com/ \{\}/media/Files/R/Rolls-Royce/documents/annual-report/2017/2017-full-annual-report.pdf (accessed on 1 October 2020).

6. Isaksson, O.; Hallstedt, I.S.; Rönnbäck, Ö.A. Digitalisation, sustainability and servitisation: Consequences on product development capabilities in manufacturing firms. In Proceedings of the International Design Conference-Norddesign, Linköping, Sweden, 14-17 August 2018.

7. Day, G.S. The capabilities of market-driven organizations. J. Mark. 1994, 58, 37-52. [CrossRef]

8. Robèrt, K.-H.; Broman, G. Prisoners' dilemma misleads business and policy making. J. Clean. Prod. 2017, 140, 10-16. [CrossRef] 
9. Filho, W.L. The New Sustainability Advantage: Seven Business Case Benefits of a Triple Bottom Line. Int. J. Sustain. High. Educ. 2013, 14. [CrossRef]

10. Davis, R. Industry 4.0: Digitalisation for Productivity and Growth, EPRS European Parliamentary Research Service, Briefing September. 2015. Available online: http://www.europarl.europa.eu/RegData/etudes/BRIE/ 2015/568337/EPRS_BRI(2015)568337_EN.pdf (accessed on 3 March 2018).

11. Neely, A. Exploring the financial consequences of the servitization of manufacturing. Oper. Manag. Res. 2008, 1, 103-118. [CrossRef]

12. Roozenburg, N.F.; Eekels, J. Product Design: Fundamentals and Methods; Wiley: Hoboken, NJ, USA, 1995.

13. Aston, W. Product design and development. Biosens. Bioelectron. 1992, 7, 85-89. [CrossRef]

14. Normann, R.; Ramírez, R. From value chain to value constellation: Designing interactive strategy. Harv. Bus. Rev. 1993, 71, 65-77.

15. Miller, W. Flexibility in Engineering Design. Insight 2012, 15, 60-62. [CrossRef]

16. Juncker, J.C. A New Start for Europe: My Agenda for Jobs, Growth, Fairness and Democratic Change; Political Guidelines for the next European Commission: Opening Statement in the European Parliament Plenary Session; European Commission: Strasbourg, France, 2014; Volume 5, p. 36.

17. European Union. Digital Transformation Scoreboard 2017: Evidence of Positive Outcomes and Current Opportunities for EU Businesses; Report from the Digital Transformation Monitor (DTM); European Commission: Strasbourg, France, 2017. Available online: https://s3platform.jrc.ec.europa.eu/-/digital-transformation-scoreboard2017-evidence-of-positive-outcomes-and-current-opportunities-for-eu-businesses?inheritRedirect=true (accessed on 1 August 2020).

18. Lasl, H.; Fettke, P.; Feld, T.; Hoffmann, M. Industry 4.0. Bus. Inf. Syst. Eng. 2014, 4, 239-242. [CrossRef]

19. Tao, F.; Cheng, J.; Qi, Q.; Zhang, M.; Zhang, H.; Sui, F. Digital twin-driven product design, manufacturing and service with big data. Int. J. Adv. Manuf. Technol. 2018, 94, 3563-3576. [CrossRef]

20. Nakicenovic, N.; Messner, D.; Zimm, C.; Clarke, G.; Rockström, J.; Aguiar, A.P.; Comolli, L. TWI2050—The World in 2050. The Digital Revolution and Sustainable Development: Opportunities and Challenges; Report prepared by The World in 2050 initiative; IIASA: Laxenburg, Austria, 2019. [CrossRef]

21. European Commission. Circular Economy Action Plan-For a Cleaner and More competitive Europe; European Commission: Brussels, Belgium, 2020; Available online: https:/ec.europa.eu/environment/circular-economy/ pdf/new_circular_economy_action_plan.pdf (accessed on 1 August 2020).

22. Swedish Government. Cirkulär Ekonomi-Strategi för Omställningen i Sverige (Circular Economy-Strategy for the Transition in Sweden. Regeringskansliet. Retrieved July 2020. Available online: https://www.government.se/ press-releases/2020/07/sweden-transitioning-to-a-circular-economy/ (accessed on 1 August 2020).

23. Chen, Y.-S.; Lai, S.-B.; Wen, C.-T. The Influence of Green Innovation Performance on Corporate Advantage in Taiwan. J. Bus. Ethic. 2006, 67, 331-339. [CrossRef]

24. Küçükoğlu, M.T.; Pınar, R.I. Positive Influences of Green Innovation on Company Performance. Procedia Soc. Behav. Sci. 2015, 195, 1232-1237. [CrossRef]

25. Hallstedt, S.I.; Isaksson, O. Material criticality assessment in early phases of sustainable product development. J. Clean. Prod. 2017, 161, 40-52. [CrossRef]

26. Byggeth, S.; Broman, G.; Robèrt, K.-H. A method for sustainable product development based on a modular system of guiding questions. J. Clean. Prod. 2007, 15, 1-11. [CrossRef]

27. Broman, G.; Robèrt, K.-H. A framework for strategic sustainable development. J. Clean. Prod. 2017, 140, $17-31$. [CrossRef]

28. Baumgartner, R.J.; Ebner, D. Corporate sustainability strategies: Sustainability profiles and maturity levels. Sustain. Dev. 2010, 18, 76-89. [CrossRef]

29. Schulte, J.; Hallstedt, S. Challenges and preconditions to build capabilities for sustainable product design. In Proceedings of the 21st International Conference on Engineering Design (ICED 17) Vol 1: Resource Sensitive Design, Design Research Applications and Case Studies, DS 87-1, Vancouver, BC, Canada, 21-25 August 2017.

30. Bansal, P.; Roth, K. Why companies go green: A model of ecological responsiveness. Acad. Manag. J. 2000, 43, 717-736.

31. Dangelico, R.M.; Pujari, D. Mainstreaming Green Product Innovation: Why and How Companies Integrate Environmental Sustainability. J. Bus. Ethic. 2010, 95, 471-486. [CrossRef]

32. Knight, P.; Jenkins, J.O. Adopting and applying eco-design techniques: A practitioners perspective. J. Clean. Prod. 2009, 17, 549-558. [CrossRef] 
33. Hallstedt, S.I.; Thompson, A.W.; Lindahl, P. Key elements for implementing a strategic sustainability perspective in the product innovation process. J. Clean. Prod. 2013, 51, 277-288. [CrossRef]

34. Pigosso, D.C.A.; Rozenfeld, H.; McAloone, T.C. Ecodesign maturity model: A management framework to support ecodesign implementation into manufacturing companies. J. Clean. Prod. 2013, 59, 160-173. [CrossRef]

35. Oliva, R.; Kallenberg, R. Managing the transition from products to services. Int. J. Serv. Ind. Manag. 2003, 14, 160-172. [CrossRef]

36. Kraaijenhagen, C.; Van Open, C.; Bocken, N. Circular Business Collaborate and Circulate; Circular Collaboration: Amersfoort, The Netherlands, 2016.

37. Timmermans, R.W.; Witjes, S. Circular Business: Collaborate and Circulate; a book review. J. Clean. Prod. 2016, 135, 699-700. [CrossRef]

38. Dachs, B.; Biege, S.; Borowiecki, M.; Lay, G.; Jäger, A.; Schartinger, D. The Servitization of European Manufacturing Industries, Munich 2012 Personal RePEc Archive. Available online: https://mpra.ub.unimuenchen.de/38995/ (accessed on 3 April 2020).

39. Neely, A.; Benedettini, O.; Visnjic, I. The servitization of manufacturing: Further evidence. In Proceedings of the 18th European Operations Management Association Conference, Cambridge, UK, 3-6 July 2011; Volume 1.

40. Antonacopoulou, E.P.; Konstantinou, E. The New Service Model: A review, a critique and a way forward. Serv. Ind. J. 2008, 28, 845-860. [CrossRef]

41. Raja, J.Z.; Bourne, D.; Goffin, K.; Çakkol, M.; Martínez, V. Achieving Customer Satisfaction through Integrated Products and Services: An Exploratory Study. J. Prod. Innov. Manag. 2013, 30, 1128-1144. [CrossRef]

42. Janssen, M.J.; Castaldi, C.; Alexiev, A. Dynamic capabilities for service innovation: Conceptualization and measurement. RED Manag. 2015, 46, 797-811. [CrossRef]

43. Buffa, E.S. Research in Operations Management. J. Oper. Manag. 1980, 1, 1-7. [CrossRef]

44. Popay, J.; Roberts, H.; Sowden, A.; Petticrew, M.; Arai, L.; Rodgers, M.; Britten, N.; Roen, K.; Duffy, S. Guidance on the Conduct of Narrative Synthesis in Systematic Reviews: A Product from the ESRC Methods Programme, Version 1; Lancaster University: Lancaster, UK, 2006; p. 92.

45. Blessing, L.T.M.; Chakrabarti, A. DRM, A Design Research Methodology; Springer: Dordrecht, The Netherlands; Heidelberg, Germany; London, UK; New York, NY, USA, 2009.

46. Wohlin, C. Guidelines for snowballing in systematic literature studies and a replication in software engineering. In Proceedings of the 18th International Conference on Evaluation and ASSESSMENT in software Engineering, London, UK, 13-14 May 2014.

47. Guest, G.; MacQueen, K.; Namey, E. Applied Thematic Analysis; SAGE Publications Inc.: Thousand Oaks, CA, USA, 2012.

48. Kohtamäki, M.; Parida, V.; Oghazi, P.; Gebauer, H.; Baines, T. Digital servitization business models in ecosystems: A theory of the firm. J. Bus. Res. 2019, 104, 380-392. [CrossRef]

49. Ren, S.; Zhang, Y.; Liu, Y.; Sakao, T.; Huisingh, D.; Almeida, C.M.V.B. A comprehensive review of big data analytics throughout product lifecycle to support sustainable smart manufacturing: A framework, challenges and future research directions. J. Clean. Prod. 2019, 210, 1343-1365. [CrossRef]

50. Parida, V.; Wincent, J. Why and how to compete through sustainability: A review and outline of trends influencing firm and network-level transformation. Int. Entrep. Manag. J. 2019, 15, 1-19. [CrossRef]

51. Loonam, J.; Eaves, S.; Kumar, V.; Parry, G. Towards digital transformation: Lessons learned from traditional organizations. Strat. Chang. 2018, 27, 101-109. [CrossRef]

52. Weking, J.; Stöcker, M.; Kowalkiewicz, M.; Böhm, M.; Krcmar, H. Leveraging industry 4.0-A business model pattern framework. Int. J. Prod. Econ. 2019, 225, 107588. [CrossRef]

53. Basirati, M.R.; Weking, J.; Hermes, S.; Böhm, M.; Krcmar, H. Exploring Opportunities of IoT for Product-Service System Conceptualization and Implementation. Asia Pac. J. Inf. Syst. 2019, 29, 524-546. [CrossRef]

54. Oghazi, P.; Mostaghel, R. Circular Business Model Challenges and Lessons Learned-An Industrial Perspective. Sustainability 2018, 10, 739. [CrossRef]

55. Lee, H.; Seo, H.; Geum, Y. Uncovering the Topic Landscape of Product-Service System Research: From Sustainability to Value Creation. Sustainability 2018, 10, 911. [CrossRef] 
56. Vandermerwe, S.; Rada, J. Servitization of business: Adding value by adding services. Eur. Manag. J. 1988, 6, 314-324. [CrossRef]

57. Szász, L.; Seer, L. Towards an operations strategy model of servitization: The role of sustainability pressure. Oper. Manag. Res. 2018, 11, 51-66. [CrossRef]

58. Hofmann, E.; Brunner, J.H.; Holschbach, E. Research in business service purchasing: Current status and directions for the future. Manag. Rev. Q. 2019, 70, 421-460. [CrossRef]

59. Hojnik, J. Ecological modernization through servitization: EU regulatory support for sustainable product-service systems. RECIEL 2018, 27, 162-175. [CrossRef]

60. Victorino, L.; Field, J.M.; Buell, R.W.; Dixon, M.J.; Goldstein, S.M.; Menor, L.J.; Pullman, M.E.; Roth, A.V.; Secchi, E.; Zhang, J.J. Service operations: What have we learned? J. Serv. Manag. 2018, 29, 39-54. [CrossRef]

61. Belvedere, V.; Grando, A.; Bielli, P. A quantitative investigation of the role of information and communication technologies in the implementation of a product-service system. Int. J. Prod. Res. 2013, 51, 410-426. [CrossRef]

62. Zheng, P.; Wang, Z.; Chen, C.-H.; Khoo, L.P. A survey of smart product-service systems: Key aspects, challenges and future perspectives. Adv. Eng. Inform. 2019, 42, 100973. [CrossRef]

63. Frishammar, J.; Parida, V. Circular Business Model Transformation: A Roadmap for Incumbent Firms. Calif. Manag. Rev. 2018, 61, 5-29. [CrossRef]

64. Bressanelli, G.; Adrodegari, F.; Perona, M.; Saccani, N. Exploring How Usage-Focused Business Models Enable Circular Economy through Digital Technologies. Sustainability 2018, 10, 639. [CrossRef]

65. Boccia, F.; Covino, D.; Di Pietro, B. Industry 4.0: Food Supply Chain, Sustainability and Servitization; Rivista di Studi Sulla Sostenibilita': Milano, Italy, 2019.

66. Opazo-Basáez, M.; Vendrell-Herrero, F.; Bustinza, O.F. Uncovering Productivity Gains of Digital and Green Servitization: Implications from the Automotive Industry. Sustainability 2018, 10, 1524. [CrossRef]

67. Mourtzis, D.; Papatheodorou, A.-M.; Fotia, S. Development of a Key Performance Indicator Assessment Methodology and Software Tool for Product-Service System Evaluation and Decision-Making Support. J. Comput. Inf. Sci. Eng. 2018, 18, 041005. [CrossRef]

68. Liu, L.; Song, W.; Han, W. How sustainable is smart PSS? An integrated evaluation approach based on rough BWM and TODIM. Adv. Eng. Inform. 2020, 43, 101042. [CrossRef]

69. Kwok, S.Y.; Schulte, J.; Hallstedt, S.I. Approach for sustainability criteria and product life-cycle data simulation in concept selection. In Proceedings of the Design Society: DESIGN Conference, Dubrovnik, Croatia, 18-21 May 2020; Cambridge University Press: Cambridge, UK, 2020; pp. 1979-1988.

70. Hallstedt, S.I. Sustainability criteria and sustainability compliance index for decision support in product development. J. Clean. Prod. 2017, 140, 251-266. [CrossRef]

71. Bertoni, M. Multi-Criteria Decision Making for Sustainability and Value Assessment in Early PSS Design. Sustainability 2019, 11, 1952. [CrossRef]

72. Eckert, C.; Isaksson, O.; Hallstedt, S.; Malmqvist, J.; Rönnbäck, Ö.A.; Panarotto, M. Industry Trends to 2040. In Proceedings of the ICED, 22nd International Conference on Engineering Design, Delft, The Netherlands, 5-8 August 2019.

73. Lewandowski, M. Designing the Business Models for Circular Economy-Towards the Conceptual Framework. Sustainability 2016, 8, 43. [CrossRef]

74. Parida, V.; Sjödin, D.R.; Reim, W. Reviewing Literature on Digitalization, Business Model Innovation, and Sustainable Industry: Past Achievements and Future Promises. Sustainability 2019, 11, 391. [CrossRef]

75. García, M.; Lavesson, N.; Grahn, H.; Boeva, V. Energy Efficiency in Machine Learning: A position paper. In Proceedings of the 30th Annual Workshop of the Swedish Artificial Intelligence Society SAIS 2017, Karlskrona, Sweden, 15-16 May 2017; Linköping University Electronic Press: Linköping, Sweden, 2017.

76. Elkington, J. Enter the triple bottom line. In The Triple Bottom Line; Routledge: London, UK, 2013; pp. $23-38$.

77. Mebratu, D. Sustainability and sustainable development: Historical and conceptual review. Environ. Impact Assess. Rev. 1998, 18, 493-520. [CrossRef]

78. Kühl, C.; Bourlakis, M.; Aktas, E.; Skipworth, H. How does servitisation affect supply chain circularity?-A systematic literature review. J. Enterp. Inf. Manag. 2019, 33, 703-728. [CrossRef]

79. Smith, D.J. Power-by-the-hour: The role of technology in reshaping business strategy at Rolls-Royce. Technol. Anal. Strat. Manag. 2013, 25, 987-1007. [CrossRef]

80. Byggeth, S.H.; Broman, G. Environmental aspects in product development: An investigation among smalland medium-sized enterprises. Intell. Syst. Smart Manuf. 2001, 4193, 261-271. [CrossRef] 
81. Condon, L. Sustainability and Small to Medium Sized Enterprises-How to Engage Them. Aust. J. Environ. Educ. 2004, 20, 57-67. [CrossRef]

Publisher's Note: MDPI stays neutral with regard to jurisdictional claims in published maps and institutional affiliations.

(C) 2020 by the authors. Licensee MDPI, Basel, Switzerland. This article is an open access article distributed under the terms and conditions of the Creative Commons Attribution (CC BY) license (http://creativecommons.org/licenses/by/4.0/). 